\title{
LA CIENCIA EN EL PENSAMIENTO DE ORTEGA ENSAYO SOBRE LA INFLUENCIA DE LA CIENCIA EN LA EVOLUCIÓN DEL PENSAMIENTO ORTEGUIANO
}

\author{
Luis García AgUILAR
}

El signo más relevante de nuestro tiempo, pocas dudas pueden caber al respecto, es el prodigioso despliegue de la Ciencia y la Técnica. Ambas se han convertido en los poderosos motores del creciente $y$, al parecer, ilimitado desarrollo de nuestra civilización. Sus logros someten nuestras vidas a transformaciones que hubieran resultado inimaginables para los hombres de las sociedades occidentales todavía no excesivamente distantes en el tiempo. Este elemento de indeclinable actualidad contribuye a hacer aún más sugestivo el tema de la ciencia, dentro del polifacético y complejo pensamiento de nuestra figura máxima de la Filosofía.

El trabajo que sigue constituye un resumen de las líneas temáticas y puntos más destacados de la tesis doctoral presentada por el autor ante la U.N.E.D., con el título arriba expresado. Su vector principal consiste en destacar algunas dimensiones epistemológicas y funcionales que surgen de la reflexión de Ortega sobre la ciencia. Las primeras giran en torno a la reactivación -hacia 1927/28 - de una concepción contructivista en su concepción del saber científico, con repercusión en su metafísica del ser y del conocer. Las segundas se centran en la función que la ciencia desempeña en el devenir humano. La crisis de la racionalidad científica y la crisis de los fundamentos de las ciencias centrales, fenómenos emergentes en nuestro siglo, entretejen una especie de telón de fondo desde donde se articula la respuesta del intelectual español: Subordinación de la Razón Pura a la Razón Vital e Histórica.

Éndoxa: Series Filosóficas, $n^{9} 7,1996$, UNED, Madrid:

Luis Garcia Aguilar: La ciencia en el pensamiento de Ortega

Ensayo sobre la influencia de la ciencia en la evolución del pensamiento orteguiano. pp. 257-278. 
El tema de la ciencia porta una singularidad muy especial en su filosofía, derivada de una divergencia interna. Su reflexión le conduce a considerar necesaria la superación de una Modernidad ya agotada. Así, en las múltiples dimensiones de su obra le vemos en disputa con las corrientes más representativas de esa Modernidad: subjetivismo, idealismo, utopismo, progresismo, etc., pareciéndole que su tiempo transitaba hacia otra diferente visión de la vida, situada «a la altura de los tiempos». Mas a pesar de conceptuar a la ciencia como el fundamento y núcleo más irreductible de la Modernidad, no muestra hacia ella análogo rechazo que hacia los otros constituyentes. Sólo discrepa de un cientifismo cuasi-religioso que pretendía de la ciencia la respuesta a los más acuciantes problemas humanos. A pesar de sus limitaciones, le aparecía la ciencia como la única instancia de la Modernidad que no había fallado al hombre y a cuya actividad en modo alguno cabía renunciar.

Una observación preliminar se hace necesaria. Su atención a la ciencia no debe inducirnos a considerar esta parte de su obra como filosofía de la ciencia en sentido estricto. Ortega es un filósofo, a secas, y no cabe presentarle como un precursor o protodescubridor de los hilos conductores de esa disciplina particular. Su reflexión acerca de los fundamentos de la Naturaleza y de toda actividad humana, se sitúa por debajo de cuestiones particulares, como pueden ser la metodología o los lenguajes lógicos, siendo su objeto las implicaciones filosóficas de la ciencia. Lo decisivo es destacar el despliegue de una filosofía fecunda, donde germinaron interesantes temas que, en tiempos más próximos y sin relación alguna con este tratamiento, recibieron una atención descollante por parte de la filosofía de la ciencia.

1. Veamos ahora, a grandes rasgos, un desarrollo tematizado que discurre al hilo del devanado de la obra del filósofo, siguiendo el transcurso de su propia vida.

Dejando al margen sus primeros pasos, hasta finales de 1906, podemos ver que sus ideas se situan en la zona de influencia de 
la escuela neokantiana de Marburgo, que retornaba a Kant a fin de fundamentar la metodología de la ciencia. De la epistemología de este colosal racionalismo sólo conviene ahora esbozar un apunte muy breve.

Centrado en un construccionismo del objeto, de origen kantiano, donde los elementos formales aportados por el sujeto moldean de manera activa la «rapsodia de sensaciones» que recibimos de las cosas, se trata de una teoría representacional para la que el conocimiento del mundo no será producto de una "presentación», tal y como éste es, sino «re-presentación» del sujeto, desde la que volver al mundo real se torna muy problemático. El sujeto construye un Mundo ideal, cuyas estructuras constituyen el objeto del conocimiento, que asume un papel normativo, de modelo al que se encuentra sometido el mundo fenoménico. Disueltos para el neokantismo los últimos restos de la noción de cosa en sí, la realidad, como es en sí misma, permanece incognoscible. Y el ideal de la construcción matemática que ahora se adopta desplaza a la física, en su concreción newtoniana, de la consideración primordial que Kant le tributara.

El pensamiento de Ortega discurre por carriles neokantianos y cristaliza en su objetivismo cultural, visión del mundo filtrada por una exaltación extrema de la cultura o «beatería cultural», como después denominaría tal propensión «moderna». El ser de las cosas se presenta como un puro ser relacional; y la matemática se consolida como la ciencia central de la Modernidad. La función de la Ciencia asume en el filósofo madrileño una tonalidad salvífica, al estilo de la visión ilustrada. Cabe sintetizarlo en dos breves fórmulas: Europa, la Europa de la Modernidad, igual a Ciencia; y esto aplicado al proyecto de regeneración patria quería decir que «España era el problema y Europa la solución» (I, 521).

La superación orteguiana del neokantismo, teoría de la ciencia imperante en la Alemania de los triunfos científicos, y su paso a la órbita fenomenológica tiene como detonante a la cuestión estética, tercer pilar kantiano de la arquitectónica de la Razón. Como el profesor San Martín destaca en sus clases, el Arte es un factor 
de distorsión en el esquema explicativo de Ortega ante el problema de España. No se ha desarrollado en nuestro país ni una ciencia ni un sistema ético fundamentados en la Razón Moderna, mas no ocurre igual con el Arte. Sin embargo, afrontado desde el neokantismo, el enigma de la estética española permanece irresoluble, quedando al descubierto una actitud subyacente de falta de veracidad intelectual que prefiere tener razón aun a costa de manipular la realidad y silenciar cuanto no pueda ser explicado desde la construcción teórica. Esa inadecuación le conduce a la superación del constructivismo idealista, para situarse en posiciones fenomenológicas. Entre ambas visiones se introduce un cambio de perspectiva muy apreciable.

Desde 1913, aproximadamente, el pensamiento de Ortega tiene por norte a la intuición, que se convierte en la función cognoscitiva principal, otorgadora del valor de verdad. Desde el nuevo punto de vista alcanzado plantea una decisiva objeción a la función constructiva ${ }^{1}$ : Como realidad previa, subyacente a los actos de juicio donde se plasma el conocimiento para el construccionismo idealista, existe el plano de la significatividad de los objetos. Es el nivel antepredicativo en que se nos ofrecen los «algos» $u$ «objetos» existentes - lo otro que el sujeto- y que constituye el mundo primordial, el más hondo de la estructura cognitiva. A su impulso, pues, se produce una revalorización del mundo real, pues anterior a cualquier problema de conocimiento ya tenemos las cosas del mundo delante. Son «realidades" indubitables que se nos presentan en la vida, en una relación todavía preteorética, y que sólo ulteriormente llegarán a convertirse en objetos, siendo la finalidad del conocimiento descubrir su ser o consistir.

Una aproximación mínima, aunque suficiente para nuestra exposición, a esta época orientada por la fenomenología puede delinearse por medio de unos pocos rasgos de especial relevancia. El más destacado es la objetividad, articulada en torno al primado

1 Para lo esencial de la crítica a esta concepción idealista, cfr. "Sensación, construcción e intuición», (XII, 487-499). 
de la intuición y al principio de la evidencia. Contrapuesto al espíritu kantiano, el catedrático madrileño asume una actitud de ontofilia propia de un sujeto que se abre hacia lo real, en toda su inabarcable complejidad. De este modo se supera el subjetivismo, error intrínseco de la Modernidad, y, como él mismo dice, se logra "conquistar la objetividad» (IV, 57). Acerca del "pensar» declara: «Su misión es reflejar el mundo de las cosas, acomodarse a ellas de uno u otro modo; en suma, pensar es pensar la verdad.» (III, 164). El pensamiento, pues, queda subordinado a las cosas, convirtiéndose lo real en el modelo y la razón en su copia. La ciencia será la transcripción de la realidad en un sistema de proposiciones probadas y su contrastación con la realidad sensible es la que otorga su valor al conocimiento científico, siendo la posición de Einstein ante el experimento sobre el viento del éter un caso paradigmático.

A lo largo de este segmento temporal operan dos teorías de la verdad imbricadas y que cabe aplicar al campo de la ciencia: $\mathrm{Su}$ conocida teoría de la verdad como descubrimiento o alétheia, expuesta en su libro más temprano, Meditaciones del Quijote; y la noción de la verdad como adecuación o correspondencia con las cosas. Si del doble haz que el pensamiento presenta, una faceta es que surge como "necesidad vital», la otra «consiste precisamente en una adecuación a las cosas y le impera la ley objetiva de la verdad.» (III, 165). No parece plantearse, todavía, ningún problema especial, de carácter óntico o epistémico, que impida el acceso al conocimiento de la realidad, conseguido en un proceso siempre inconcluso por propia naturaleza.

La noción de perspectivismo es clave de bóveda de la concepción epistemológica, conectada a su inserción en la esfera fenomenológica, constituyendo elemento central de su doctrina, mantenido ya a lo largo de toda su obra. Ortega aduce la «magnífica confirmación» (III, 200, n.) de su doctrina perspectivista por obra de la teoría de la Relatividad. Sin embargo no parece quedar excesivamente clara su justificación, por lo que a la teoría física respecta, al no haber obtenido el tratamiento de este punto - en mi opinión- la intensión que quizá hubiera sido menester para 
mostrar su verdadero sentido. Cabe añadir que el conjunto de rasgos definitorios de esta etapa se halla inmerso en una actitud vitalista y deportiva, a la que simplemente nos es dado aludir.

Desde la nueva perspectiva vitalista, inspirada por la fenomenología, se produce un giro radical en el vector funcional, auspiciado por la crisis de la racionalidad científica, fenómeno histórico de enorme complejidad, del que sólo parece oportuno resaltar su aspecto resultante de crisis de fe en la ciencia. El siglo XIX habia llegado a sacralizar a la ciencia, convirtiéndola en una nueva religión, sustituto de la auténtica fe religiosa desvanecida, como fe viva, en el Renacimiento. Pero la inutilidad de la Ciencia, en su mejor paradigma, el físico-matemático, para dar respuesta a las graves cuestiones de todo orden planteadas ante la humanidad en la pasada centuria y multiplicadas en la nuestra, hizo quebrar la "gran fe» en la Ciencia y en la Razón Pura que le subyace. El estudio del ser de lo fijo, propio de la razón naturalista, paradigma en que también se miraban las Ciencias del Espíritu, invalida cualesquiera soluciones a problemas de la esfera humana, caracterizada por un ser fluido, móvil, en una palabra, histórico.

Este período femonenológico contiene una importante vertiente de análisis socio-histórico, al hilo e impulso de la «circunstancia», generando obras tan importantes como España Invertebrada, El tema de nuestro tiempo, o La rebelión de las masas. Habiendo partido de una visión salvífica de la ciencia, desemboca ésta en un modesto lugar de segundo orden. En la nueva reorganización de la escala de valores, la racionalidad científica pierde el carácter de hegemonía absoluta, como núcleo central de la cultura, y pasa a subordinarse a la razón vital, pronto destacada en su otra dimensión de razón histórica. Las líneas principales de este proceso van a permanecer ya como elementos característicos de su reflexión.

Ortega, espíritu ávido de conocimiento e instalado por voluntad propia en el nivel exigido por su tiempo, se mantenía alerta ante los nuevos problemas que surgían en los diferentes ámbitos de la actividad humana, los de la Ciencia en destacado lugar. Recordemos aqui una acotación autobiográfica muy reveladora, 
efectuada tras un breve recuerdo a sus estudios en Alemania: "Luego he continuado años y años sumergido en la ciencia alemana hasta casi ahogarme.» (VIII, 20). Esta faceta de perseverante atención al desarrollo de la ciencia, a la que las palabras de una figura de las dimensiones de Heidegger ${ }^{2}$ otorgaban reconocimiento pleno, es la actitud que se halla en la base de su receptividad ante el fenómeno de la crisis de los fundamentos de las ciencias, fenómeno que conforma un nuevo marco de referencia para el conocimiento científico. Desde los últimos decenios del siglo XIX el mismo desarrollo de las ciencias hace aflorar problemas que proyectan su sombra más allá de su localización particular. Nuestro filósofo, en 1915, les denomina "problemas nodales», señalando varios ejemplos, de entre los que tomamos, «el espacio de n-dimensiones y el infinito actual de Cantor, en matemáticas. Las experiencias de Michelson sobre la Relatividad, en física.» (XII, 345)

Por mi parte, me he limitado a destacar dos núcleos en que los problemas del saber contemporáneo se condensan, dentro de las ciencias principales que, según diría Ortega, «constituian la acrópolis, la ciudadela de la inteligencia o razón... la física, la matemática y la lógica.» (XII, 286). La crisis se desplegaba al aparecer anomalías que entraban en colisión con principios hasta entonces indiscutidos. Cuando las teorías se vuelven inútiles para dar razón de la realidad se impone una "revisión" de los principios constituyentes. $Y$ para esta reforma no bastan los métodos y principios de cada ciencia. Los problemas irradiados sobrepasan los límites disciplinares, alcanzando concepciones tan arraigadas como el Tiempo, el Espacio, o las relaciones entre la geometría y el mundo. La Filosofia asume entonces un papel clave de indagación en el subsuelo de la ciencia, idea directriz que ejemplifica en la física relativista,

${ }^{2}$ En la nota necrológica afirmaba el filósofo germano: "La discusión puso de relieve lo muy versado que Ortega estaba en las Ciencias". (M. Heidegger. «Encuentros con Ortega y Gasset». Clavileño, núm. 39, pág. 2. 1956).Cr. V. Marrero. Ortega, filósofo "mondain», p. 350. 1961. 
subrayando la necesidad de Einstein, frente a Newton, de saturarse de filosofía, centrada en Kant y en Mach.

El primero de los núcleos problemáticos aludidos es el fracaso final del programa logicista, encrucijada donde se funden estrechamente los intereses de la lógica y de la matemática. Era de la máxima importancia dotar a la aritmética de leyes formales adecuadas, siendo Frege el hombre decisivo al crear el primer sistema completo de lógica matemática. Pensadores como Russell y Whitehead desarrollaron sus potencialidades. Bajo la perspectiva matemática, subyacía un problema de no pequeña magnitud: En última instancia, cabe decir que el teorema de Cantor se halla en la base de una antinomia que, al hilo de la inconmensurabilidad entre infinitos de orden distinto, se cierne sobre la teoría de conjuntos. Cualquiera que sea la versión de esta antinomia, de entre las múltiples conocidas, conduce a contradicción, invalidando todo sistema formal que la contenga. Si la infinitud de los números naturales no deja de plantear dificultades, la naturaleza de los números reales, con la cardinalidad del continuo, conjunto infinito no-numerable, las multiplica de tal modo que se acabó por desembocar en la constitución de varias «escuelas» dentro de la matemática y su filosofía, según los grados de infinitud aceptados, y a las que acechaban la contradicción o la limitación. Este problema, ligado al orbe de la filosofia de la matemática, ha quedado abierto, como el de los universales, del que constituye una versión actualizada.

Mas el proyecto logicista, comenzado por Frege y que podemos remontar a Leibniz, quedó definitivamente saldado con un fracaso. En los textos orteguianos se puede observar su sensibilidad a esta cuestión, que culmina con el célebre teorema de Gödel sobre la incompletitud de la matemática, al que nuestro filósofo se refiere, implícita o explícitamente ${ }^{3}$, en dos ocasiones. La consecuencia que

${ }^{3}$ En V, 528. Apuntes sobre el pensamiento: su teurgia y su demiurgia, 1941; y en IX, 663. "Pasado y porvenir para el hombre actual». 1951, respectivamente. 
extrae -1941 - es que la empresa de construir la lógica se había vuelto inviable debido a que los elementos de i-logicidad descubiertos en la lógica volvían a ésta inexistente. Manifestaciones desproporcionadas, sin duda y máxime si las tomamos aisladas, referidas a los principios fundantes adquieren, sin embargo, singular actualidad, como lo muestran los debates en torno al pensamiento algoritmizado, propio del modelo del computador.

El «desvanecimiento del saber físico» es la otra gran crisis de fundamentos del conocimiento científico que Ortega refleja. Es un proceso iniciado en el pasado siglo dentro de la teoría de campos que, a través del resultado negativo del experimento MichelsonMorley para determinar el viento del éter, condujo a la Relatividad, teoria que trastrocaba ideas consideradas como la realidad misma. Pero sólo fue el primer acto de una revolución, todavía dentro de los marcos clásicos. El segundo, la teoría cuántica, quebró estos marcos y ahondó los problemas. Las investigaciones de Planck y de Einstein superaron la unilateral concepción continuista de la radiación electromagnética, cuya aplicación a la emisión de energía por parte de los cuerpos negros no daba cuenta de los hechos observados. A partir de entonces quedó establecida su constitución dual, más tarde extendida a la propia materia, de onda y partícula, conjuntamente.

En la obra de Ortega se hallan referencias a algunos de los tópicos más conocidos, condensación de los problemas interpretativos de las nuevas investigaciones, sin que por ello quepa llevar las cosas demasiado lejos. Se ocupa de puntos básicos como el indeterminismo; la debilitación del principio de causalidad; las relaciones de incertidumbre; o la interacción del sujeto en el experimento. Fundamentos inconmovibles se ponían «en radical cuestión», quedando bajo sospecha. Las chocantes afirmaciones orteguianas sólo venían a reflejar las opiniones de los físicos en sus «revistas más técnicas" (V, 276): las crecientes dificultades surgidas en las relaciones entre conocimiento y realidad. Un matiz de dramatismo se desliza en las apreciaciones de Ortega, que parecen quizá algo excesivas. Pero ocurre que su atención se dirige al contexto global 
de la civilización, del que hay recordar sus terribles convulsiones. La ciencias centrales - física y lógica - le aparecían como la "cajafuerte» del hombre occidental, y de ahí la gravedad implicada por la crisis de sus fundamentos.

Conviene completar esta panorámica aludiendo a la crisis del científico en cuanto individuo: es el problematismo que se sitúa bajo la referencia de la "barbarie del especialismo", tratada sobre todo en La rebelión de las masas, y que podemos correlacionar con algunos puntos de la noción -ya clásica en filosofía de la ciencia- de "ciencia normal", puesta en circulación por Thomas $S$. Kuhn.

2. A partir del año 1929 se manifiesta otro cambio de inflexión, con constantes críticas a puntos centrales de la Fenomenología, como la primacía concedida a la conciencia refleja en la constitución del "mundo", según interpretación equívoca, aunque no de su exclusiva responsabilidad. En la fenomenología ve la última y más depurada expresión del idealismo subjetivista propio de la Modernidad, a la que era menester superar. Éste es el eje central, filosófico, de referencia, pero sin olvidar que otros factores, de muy diversa índole, colaboran a una variación de rumbo, ya de menor entidad que la anterior de 1913.

La concepción gnoseológica que Ortega tiene de la ciencia experimenta una transformación a finales de 1927. En su ensayo "La Filosofía de la Historia de Hegel y la historiología», aparece una reactivación del constructivismo, inoperante en su visión ya desde hacía más de un decenio. Se trata de un cambio de énfasis, aunque de gran importancia, coexistente con el vector de objetividad asumido desde su visión fenomenológica, lo que complica un tanto las cosas. La tensión entre esos dos polos epistemológicos dejará latente un substrato de dificultades. Su concepción del conocimiento científico se va a configurar como un conocimiento simbólico, obra de un costructivismo de claras connotaciones instrumentales. Esos atributos de constructivismo, simbolismo e instrumentalismo son los elementos que, en adelante, adquieren el rango 
de ideas-fuerza y conforman la fisonomía de la concepción orteguiana sobre el tema.

En múltiples lugares de su obra podemos hallar esta idea directriz de que la ciencia - la física en primer y muy destacado término- es construcción, presentándose con variados matices y perspectivas diversas, incluso ostentando en alguna ocasión un cierto equilibrio con el aspecto empírico y experimental. Su núcleo central queda expresado con claridad y permanecerá ya inalterado. Ortega, en el aludido texto sobre Hegel y la historiología ${ }^{4}$, declara taxativamente: «Ciencia no significa jamás "empiria", observación, dato a posteriori, sino todo lo contrario: construcción a priori.» (IV, 527). Esta construcción es obra de la fantasía y se halla muy cercana en parentesco a la poesía.

El simbolismo, por su parte, se convierte en línea temática que reitera ${ }^{5}$ la comparación del conocimiento del universo con el que cabe obtener de las prendas depositadas en el guardarropa de un teatro por medio de las fichas que identifican su lugar de colocación. Entre conocimiento y Naturaleza habrá correspondencia, pero será mínima, sólo simbólica. El físico asumirá el papel de "guardarropista ciego del Universo material» (VIII, 80) y cabe dudar, desde la nueva perspectiva epistemológica, que "conozca la Realidad» si por conocimiento se entiende presencia en la mente del ser de las cosas.

El hilo conceptual del instrumentalismo de las teorias científicas también conlleva un componente utilitario, pragmatista, adherido al «buen funcionamiento". El saber de la ciencia moderna responde al programa de «salvar las apariencias", proclamado por Platón y que brilla con intensidad en algunos periodos de la historia de la ciencia.

\footnotetext{
4 Publicado en 1928.

5 Este ejemplo persiste en el tiempo, pues lo propone en su curso ¿Qué es filosofí?, de 1929, (VII, 302-3); lo vuelve a exponer en su relevante texto de 1937, "Bronca en la física» (V, 277); y también lo incluye en su libro La idea de principio en Leibniz y la evolución de la teoria deductiva, de 1947 (VIII, 80).
} 
No cabe duda de que se ha producido un vuelco. En 1923 había elogiado la actitud de Einstein porque «invierte la relación inveterada que existía entre razón y observación» (III, 241), afirmando que la razón pura, construcción a priori o geometrización debe subordinarse a la realidad. Para su visión de madurez, en cambio, el factor primordial se traslada desde la realidad -observación o experimento- a las "construcciones imaginarias" de las teorías ${ }^{6}$.

La de Ortega es una concepción de constructivismo mucho más genérica y vaga que la decantada en nuestro tiempo, con la que no es equiparable, pues esta última se halla sometida a condicionamientos y formalizaciones más rigurosas. El cambio de perspectiva epistemológica sobre la ciencia tiene su origen en los problemas de una historia hipertrofiada de hechos, lo que es tanto como decir desarrollada en el círculo de su periferia empírica. Pretendía el pensador madrileño elevar a la Historia al rango de ciencia, incluso al de ciencia paradigmática, introduciendo una teorización vertebradora, que es el elemento central de toda ciencia. Se trataba del correlato de su proyecto de constituir una razón histórica que contuviera y fundamentara a la razón pura, fisico-matemática o natural.

El constructivismo orteguiano en los campos de la ciencia no es, sin embargo, un mero retorno a la ideación kantiana, cuyo centro es la construcción del objeto. El espiritu que anima a nuestro filósofo se halla en las antípodas del kantismo: si Ortega llega al constructivismo es en virtud de un imperativo de fidelidad a lo real, en este caso al desvelamiento por la ciencia de una realidad que na cabía ignorar. De entre las declaraciones de recusación del constructivismo kantiano hay una muy explícita, en la que se afirma que el conocimiento no es -entre otras cosas-, «una construcción de la cosa como supusieron Kant, los positivistas y la es-

${ }^{6}$ Cfr., p.e., «Bronca en la física», 1937. 
cuela de Marburgo»? A la cuestión crucial de si Ortega retorna a posiciones kantianas, hemos de responder, en lo sustancial, de forma negativa, aun cuando, con los matices de rigor, caben también ciertas afinidades.

La tesis que destaca la dimensión objetiva de lo real, entroncada a la noción de verdad como adecuación, aludida ya en páginas anteriores, puede tener como lema central un texto de 1924 que lo reitera: «El pensamiento tiene la misión primaria de reflejar el ser de las cosas.» (II, 482). La construcción imaginaria debe subordinarse a lo real, pareciéndole -en aquellas fechas- lo contrario una falsificación. Posición de objetividad que mostrará sus fisuras cuando el ser de las cosas, en determinados orbes como p.e., los de la física atómica o la cosmología, no pueda ser simplemente reflejado y haya que construirlo. El referente objetivo del conocimiento científico, o sea, la Naturaleza, pierde consistencia y la noción de verdad como «adecuación», en los sectores de la física cuántica, pongamos por caso, deja de ser aplicable, incompatible ya con el carácter de simbolismo instrumental que nuestro filósofo le atribuye. Un texto de su ensayo Ideas y creencias - año 34- nos parece en extremo revelador sobre esta cuestión. Alli afirma: «No es posible, como en tiempos más venturosos, definir galanamente la verdad diciendo que es la adecuación del pensamiento con la realidad.» $(V, 402)$. Esta noción afecta, singularmente, al orbe de la física, como claramente señala, siguiendo a ese pasaje la afirmación sobre la certeza del físico de que sus teorías no las hay en la realidad.

$\mathrm{Al}$ entrar el estudio del substrato básico del universo material por la vía de la teoría cuántica fallaban los intentos de acceder siquiera a una representación de la realidad profunda. Era un mundo en el que la razón humana quedaba en absoluto desorientada. Y las opiniones de figuras como Bohr, Heisenberg, Gamow, por poner algún ejemplo, no hacen más que subrayarlo. Ortega ha

${ }^{7}$ IX, 372. Origen y epilogo de la filosofía. 1943-46. (El subrayado es nuestro) 
asumido el carácter e implicaciones filosóficas de la teoría cuántica, cumbre de la ciencia física. A ello habría que sumar los elementos de crisis derivados de los problemas «nodales" que aquejaban también a la lógica y a la matemática, tal y como él mismo recuerda, p. e., en $1949^{8}$. La comprensión del ser de las cosas -a veces también su existencia-, se ha vuelto problemática, fenómeno de la mayor importancia porque afecta a la solidez misma del mundo corpóreo en que vivimos. En el cambio de rumbo del filósofo madrileño se deja sentir -es el nervio de esta tesis- la influencia de la nueva dinámica cognoscitiva originada por la inédita y paradójica faz que presentaba la realidad física, sin precedente en la historia del pensamiento y que venía avalada por un saber experimental y no puramente conceptual. En mi opinión, cualquier interpretación que no tome en cuenta este factor corre el riesgo de dejar opacas ciertas tensiones latentes en su teoría del conocimiento.

Reconozcamos que acaso Ortega ha llevado un tanto lejos la literalidad de las declaraciones de los propios sabios atómicos, lo cual nos conecta con la espinosa cuestión de la validez filosófica de cuanto en los físicos excede la propia esfera de su ciencia. Las opiniones al respecto son contradictorias. Sea como fuere, la consecuencia es que las características de un segmento, aunque central, de la ciencia física son extrapoladas a la física toda, después a la ciencia íntegra y sus ecos acaban resonando en su visión metafísica.

3. En el campo onto-epistemológico la empresa orteguiana se declara como un intento de superar las dos posiciones tradicionales de la historia de la filosofía: realismo antiguo y medieval, e idealismo moderno. A los ojos de nuestro pensador ambas cometen similar error, proyectándolo en diferentes regiones ontológicas: considerar Realidad sólo aquello que es independiente. Para el rea-

${ }^{8}$ Cfr. IX, 569. «Sobre un Goethe bicentenario». 
lismo lo era el mundo; para el idealismo, el pensamiento. La tesis metafísica de Ortega -expresada en la metáfora de los Dioses conjuntos ya en 1916 (XII, 388)-, resalta la coexistencia mutua "del yo con las cosas». Su elemento nuclear radicará en que "mundo independiente, pensamiento independiente, no existen.» (XII, 181).

No parece ocioso diferenciar dos dimensiones ónticas del ser, a cada cual concierne un modo de acceso. La principal corresponde al mundo primario, pre-teorético, en que nos relacionamos con las cosas a través de su actuación sobre nosotros - y viceversa. En este mundo patente el ser consiste en su "servicialidad"; las cosas aquí sólo tienen un «ser instrumental», un ser para mí. La otra dimensión del ser radica en la consistencia propia de las cosas, lo que ellas puedan ser por si y para si, sin relación al sujeto, es decir, el ser independiente que en lo concreto buscan las ciencias $y$, en lo general, la filosofia. En este punto aflora una particular dificultad. El auténtico en sí de las cosas no lo tenemos patente $y$, según su visión de madurez, tiene que inventarlo o construirlo el pensamiento del sujeto. El ser de las cosas será «un esquema intelectual $"$, una pura construcción de la fantasía, al igual que los sueños o la poesía. El meollo de la cuestión es que, como nuestro autor declara, "ser no es ninguna cosa por sí misma ni una determinación que las cosas tengan por su propia condición y solitarias.» (IV, 56)

Mas esta respuesta no permanece unívoca, complementándose con afirmaciones acerca de que lo construido o puesto por el sujeto corresponde, no obstante, a los rasgos propios del objeto, descubriéndonos su ser. Pero construir el ser es completamente opuesto a descubrirlo o desvelarlo. Lo primero es faena que efectúa el sujeto desde si mismo. Lo segundo es insuflar al puro constructivismo elementos objetivantes -en grado y alcance variable-, que equivale a declarar que los aspectos «descubiertos» en el ser de las

9 "¿Qué es la vida?", 1930-31. Texto de un curso no incluido en las O.C., y recogido en el volumen ¿Qué es conocimiento?, pág. 157. R. de O. en Alianza Editorial. Madrid, 1992. 
cosas son ellos por sí, que allí residían y que el sujeto se limita a ponerlos de relieve, a hacerlos aparecer. La resolución de intentar combinar facetas tan dispares resulta ser una solución que se vuelve harto problemática y poco satisfactoria. Por insignificantes e infinitesimales que pudieran ser los ingredientes de objetividad deslizados en el vector constructivista de su pensamiento, siempre poseerán la suficiente entidad para hacer traspasar ese límite, a la vez tan sutil y nítido, que separa a las diferentes posiciones filosóficas, cuya coexistencia - siquiera parcial-, implica un cierto grado de inconsistencia.

El nudo de este interesante asunto, aquí apenas esbozado, se halla en una proyección -quizá no del todo aplicable, creo yo-, a un modo de ser de las cosas cuyo sentido es de invarianza y permanencia, de los atributos de un ser de tipo relacional, operante en el mundo antepredicativo de la vida. Un ser relacional del que se olvida el en sí o peculiar estructura que proporciona a las cosas su identidad.

En síntesis, la mencionada superación de ambas posiciones filosóficas, desde este ángulo, no parece quedar bien resuelta. Su situación fluctuante parece obvia, considerada bajo el prisma de una concepción general que nos es habitual, visión dualista, exclusiva, del esto o aquello, sobre la que el pensamiento de la física clásica fundaba su "descripción unívoca de la Naturaleza» ${ }^{10}$. Mas ocurría que esta concepción dejaba de tener vigencia plena, siendo desplazada por la nueva interpretación de la realidad basada en la ley de los cuántos. En última instancia, el problema planteado por las tesis orteguianas que ahora nos ocupan se decantaba en torno a la existencia independiente de un ser de las cosas. Bajo la nueva perspectiva cuántica y en su ámbito de aplicación, opera el Principio de complementariedad: ya no hay lo uno o lo otro, en forma independiente, sino que la realidad consiste precisamente en los

${ }^{10}$ De entre las varias obras que hemos manejado acerca del tema de la ciencia física, destacamos, por su claridad, el magnifico libro de divulgación elaborado por John Gribbin, En busca del gato de Schrödinger. 
dos a la vez, en parejas complementarias, como onda-corpúsculo; posición-velocidad; o la más "filosófica" y discutida relación observador-experimento.

Entre estos postulados del mundo cuántico y la teoria orteguiana de la coexistencia mutuamente dependiente de sujeto y objeto, nos parece observar un cierto aire de familia, una similitud significativa. Enfocada la visión de nuestro filósofo desde los presupuestos del nuevo paradigma cuántico se nos torna más plausible su explicación. Si bien de sus textos no cabe afirmar un deliberado intento de transcribir en clave filosófica las implicaciones gnoseológicas de las nuevas teorias físicas, datando, además, su empresa de superación del pensamiento tradicional de fecha anterior a la divulgàción de la interpretación cuántica de la naturaleza, resulta indudable su apertura al complejo modo de ser de la realidad allí presentado. Parece renovarse, en cierta medida y sentido, la convergencia con la teoría de la relatividad, aunque esta vez no hallamos alusión alguna sobre una posible confirmación de sus ideas por parte de la nueva física, cual ocurriera con la teoría einsteniana.

La interpretación "ortodoxa» que de la física cuántica hace la Escuela de Copenhague fue expuesta públicamente por Niels Bohr en el año 1927 y tomaría definitivamente carta de naturaleza durante el V Congreso Solvay de Física, en octubre de ese mismo año. Esa fecha parece constituir un hito destacado de la época. En adelante, también se despliegan los desarrollos de la teoría del conocimiento de nuestro filósofo. A mi modo de ver, es receptivo a un modo de interpretar la realidad, inferido desde los nuevos fenómenos que, en su esfera, sacan a la luz las investigaciones físicas, lo que sugiere un cierto isomorfismo o paralelismo de orientación - probablemente no casual- entre concepciones de distinto nivel y extensión que parecen formar parte de una misma matriz conceptual, producto de la época y situada «a la altura de los tiempos».

4. Las dificultades implicadas en el constructivismo asumido se proyectan también fuera del campo de la ciencia, al hilo de las 
funciones psicológicas de ideas y creencias, que constituyen elementos centrales de su teoría del conocimiento definitiva, instrumentalizada al servicio de la metafísica de la Vida. De su importante entramado aquí sólo es factible aludir a un punto problemático: el mundo como enigma. Siguiendo los trabajos del profesor San Martín $^{11}$ cabe distinguir dos concepciones complementarias de la noción de creencia, derivadas de dos secuencias diferentes de su implicación con las ideas y ligadas a los aspectos vital e histórico de la razón, respectivamente. Destaquemos esta última relación, predominantemente proyectada sobre el ser de las cosas. Parte el hombre de su enfronte a la realidad desnuda que le es desconocida, siéndole el Mundo algo «absolutamente extraño e inhóspito" (VII, 176). Todo conocimiento acerca del ser o consistencia de las cosas es interpretación que ha ido construyendo de ese "primario y preintelectual enigma» $(V, 400)$. Sucesivas interpretaciones se han ido decantando a lo largo de la historia: magia, mito, religión, ciencia o filosofia. Son redes conceptuales que el pensamiento arroja sobre la realidad para aprehenderla, mas si deconstruimos las capas depositadas sólo nos volvemos a encontrar con el puro misterio. El conocimiento adquiere así una faz simbólica, incapaz ya de capturar lo real en su propia mismidad, reduciéndose a una manipulación cada vez más ajustada de las cosas.

Aunque conviene no olvidar la línea de objetividad entremezclada con el componente constructivista desarrollado al hilo de las ideas, es necesario resaltar que la conclusión destilada de nueva concepción epistemológica sobre la ciencia resulta demoledora para su dimensión de conocimiento, alejándola de esta esfera e impulsándola en dirección al plano estrictamente funcional.

Cuando de la física - paradigma de ciencia - se afirma que «lo que esta ciencia tiene de conocimiento es algo meramente negativo" (IV, 532), es que se asiste al desvanecimiento del saber cientí-

11 Javier San Martín. "Ideas y creencias. Comentario a un texto de Ortega". (Inédito). 
fico y la Razón Pura, su centro cordial, se obscurece en la misma medida que el filósofo ilumina otra de sus facetas asociadas, la Razón Técnica. La física, en cuanto ciencia, se convierte en substrato necesario para hacer posible la Técnica, actividad de progresiva importancia para nuestro autor. El ejemplo máximo lo podemos observar en su texto sobre Leibniz: «La Física, ya dije, es la técnica de las técnicas y el ars combinatoria para fabricar máquinas. Es un saber que con el conocer apenas tiene nada que ver.» (VIII, 279).

Nos hallamos ante un proceso en el que convergen los temas de su antropología metafísica y cuya principal tesis ${ }^{12}$ es que el hombre resulta ser un extraño a la naturaleza que le circunda, condenado a ser «un extranjero». El tema del hombre como el Extraño le acerca, sobre todo en sus resonancias emotivas, a una tradición filosófico-religiosa de larga data, de la que el Gnosticismo sería uno de sus componentes más conspicuos. Pero el ser del hombre orteguiano no se fundamenta en ningún mito religioso, sino en un mito naturalista ${ }^{13}$, evolucionista - aunque antidarwiniano-, que no proporciona otra patria a la que poder retornar.

Por más que originado en la naturaleza, el hombre «no pertenece a la naturaleza». Desgarrado entre su mundo interior, el verdaderamente humano, y el exterior de la naturaleza, ha acabado por transformarse en un "centauro ontológico». Infeliz al haber quedado desencajado de su medio, anhela crearse otro mundo con el que poder coincidir, donde dejar de ser el extranjero. Ésta es la idea de la felicidad, inalcanzable con plenitud. En este punto se revela la trascendencia de la Técnica, pues su misión consiste en posibilitar el intento, siempre incabado, de inserción del hombre en el Mundo por medio de su transformación. Y como la física, en opinión del

12 Idea que, atravesando el pensamiento maduro del filósofo madrileño, cristaliza en diversos trabajos, como sus cursos Unas lecciones de metafísica (1932-33), En torno a Galileo (1933), Meditación de la técnica (1933), "La razón histórica" (Buenos Aires, 1940), Una interpretación de la historia universal, (1948-49); y su libro La idea de principio en Leibniz (1947).

${ }^{13} \mathrm{Cfr}$. "El Mito del Hombre allende la técnica", (IX, 617-624); o también Una interpretación de la historia universal (IX, 170 y 189-190). 
pensador madrileño, es la posibilidad de una técnica ilimitada, se convierte la física, como nos dice, en «el organon de la humana felicidad y la instauración de esta ciencia -salvas intervenciones sobrenaturales que respeto- es el hecho más importante de la historia universal.» (IX, 584).

Se desemboca, asi, en el problemático ser de la ciencia. Su naturaleza, una vez desvanecido su carácter de Conocimiento, influido el filósofo por la noción griega del mismo, es una cuestión que permanece irresuelta. Queda clara su función, pero su consistencia, correlativamente, se obscurece. Traspasada la ciencia a la esfera instrumental, se forma un continuum que engarza a la ciencia pura con la técnica. Estamos ante una instrumentalidad desplegada en tres direcciones al servicio de la vida; construcción teórica que responde al lema de «salvar las apariencias» de la realidad; y por último, «técnica» encargada de propiciar y facilitar la labor de la Técnica. Al hilo de esto último la ciencia vendría a constituirse, en nuestra interpretación personal, como la "matemática" de la técnica. La asimilación, siquiera parcial de la ciencia física a la matemática, subraya la dimensión de construcción teórica que reduce al mínimo imprescindible su conexión con el mundo real. El «mundo interior» que es la ciencia adquiere el perfil de una "gran máquina» o artefacto teórico que se repliega sobre sí mismo. Pero un sistema sin referentes es una pura sintaxis o, estirando un tanto el término, una "gramática" de un lenguaje sin significados. En esto parece haberse convertido la estructura teorética de una ciencia carente ya de los tradicionales anclajes en el universo físico real, mera correspondencia simbólica que lleva a una situación aporética donde la dificultad se cierne sobre la referencia.

Ahí parece alojarse un elemento de disonancia. El problema es que se nos ha vuelto opaco el saber a qué corresponde entonces el conocimiento de ese conjunto sistemático de estructuras legaliformes que son las teorias en que la ciencia, ante todo la física, ha cristalizado. Ciertamente, es muy probable que la opinión de Ortega sobre este punto contenga alguna dosis de exageración. En relación crítica con todo ello habría que preguntarse: ¿No funda la 
ciencia proposiciones tan certeras y absolutas como aquellas otras del ámbito primario del mundo de la vida? La ciencia contiene conceptos descriptivos de la realidad. A la captación de esta realidad, generalmente inaccesible con los solos sentidos humanos, se halla asociada una técnica cuya utilización hace posible el desarrollo del conocimiento científico. El resultado es abrirnos dimensiones de la realidad vedadas al hombre en cuanto ser natural.

La cuestión clave radica en si cabe considerar sólo actos presentativos, de evidencia inmediata, fundante de verdad, a los que nos proporcionan nuestros sentidos corporales, o bien debemos extender tal decisiva cualidad también a la realidad revelada con ayuda de la técnica, aun con las reservas adecuadas a su ilimitada versatilidad. Lo que se halla en juego es la salida de un itinerario conducente a un antropocentrismo hermetizado. Una posibilidad abierta la señala García Bacca, en su libro Elogio de la Técnica ${ }^{14}$, aludiendo a una «fenomenología activa» que usa de la técnica —en su sentido más amplio- para el análisis de lo profundo de la realidad en que ésta se desencubre. Verdadero "desencubrimiento", obra de una técnica auténticamente creadora y no sierva ni imitadora de lo natural, que se expresa en su punto culminante: «Las explosiones atómicas planificadas son explosivas del ser real, del profundo; son explosiones ónticas». Así, se vendria a superar una "fenomenología pasiva» que, sirviéndose de una técnica todavía naturalista, sólo descubre el ser de las cosas «en plano de co-presencia, con la natural preeminencia de las potencias cognoscitivas».

Por desgracia, sobre esta relevante y tan actual temática de la conceptuación de la ciencia no hallamos en la obra orteguiana profundización ulterior alguna. Es un problema que permanece abierto.

Para finalizar, subrayemos una inalterada convicción de nuestro filósofo que cabe destilar de su obra: la Razón, aun reconociendo

${ }^{14}$ Cfr. pp. 90-104. 
sus límites y las grandes dosis de irracionalidad existentes en el Universo, es un elemento irrenunciable para la construcción de la vida $y$ sin su contribución no puede haber futuro digno del Hombre.

\section{BIBLIOGRAFIA}

En la imposibilidad práctica de reseñar la bibliografía completa, me limito a algunas indicaciones significativas para el núcleo de la temática tratada.

ANDRADE e SILVA, J. y LOCHAK, G., Los cuantos. Ediciones Guadarrama. Madrid, 1969.

BENAVIDES, M., De la ameba al monstruo propicio. Universidad Autónoma de Madrid, 1988.

CEREZO, P., La voluntad de aventura. Ariel. Bancelona, 1984.

GaMow, G., Uno, dos, tres...infinito. Realidades y especulaciones de la ciencia. 1947. Espasa Calpe. Madrid, 1969.

GARCía BACCA, J.D., Elogio de la técnica. Editorial Anthropos. Barcelona, 1987.

GRIBBIN, J., En busca del gato de Schrodinger. Bantam Books. 1984. Salvat Editores. Barcelona, 1988.

HEISENBERG, W., La imagen de la Naturaleza en la física actual. Rowohlt Verlag. Hamburgo, 1955. Ediciones Orbis. Barcelona, 1985.

HUNTER, G., Metalogica. Editorial Paraninfo. Madrid, 1981.

KNEALE, W. y M., El desarrollo de la lógica. The Clarendon Press Oxford, 1961. Editorial Tecnos. Madrid, 1980.

KLHN, T. S., La estructura de las reooluciones científicas. University of Chicago Press, 1962.- F.C.E. México, 1978.

LASAGA MEDINA, J., "Las creencias en la vida humana». Éndoxa: Series Filosóficas, $n^{\circ}$ 4. UNED. Madrid, 1994.

MARIAS, J., Ortega."* Las trayectorias. Alianza Editorial. Madrid, 1983.

MASON, St. F., Historia de las Ciencias. Alianza Editoria. Madrid. 1986. 5 vols.

MORÓN ARROYO, C., El sisteme de Ortega y Gasset. Ediciones Alcalá. Madrid, 1968.

PENROSE, R., La nueor mente del emperador. Oxford Univesity Press, 1989. Editorial Mondadori. Madrid, 1991.

SAN MARTIN, J., Ensayos sobre Ortega. UNED. Madrid, 1994.

THELL, Ch., "¿Qué significa 'constructivismo'?». Teoreme, VII-1-1977.

ZUBIRI, X., Naturaleza, Historia, Dios. 1'ed.: Editora Nacional, 1944. Alianza Editorial. 9! ed. Madrid, 1987. 